\title{
Ultrasonic Scission of Deoxyribonucleic Acid in Aqueous Solution II. Precipitational Fractionation and Molecular Weights of Sonicated Samples
}

\author{
Kiyohiro FUKudome, Kiwamu YAMAOKA,* Kenichiro NiSHIKORI, \\ Hidekazu TATEhata, and Osamu Yamamoto** \\ Faculty of Science, Hiroshima University, Higashisenda-machi, Naka-ku, \\ Hiroshima 730, Japan \\ ** Research Institute for Nuclear Medicine and Biology, \\ Hiroshima University, Kasumi-machi, Minami-ku, \\ Hiroshima 734, Japan
}

(Received May 7, 1985)

\begin{abstract}
Four sonicated calf thymus deoxyribonucleic acid (DNA) samples irradiated at different energies, whose molecular weights $M_{w}$ were $5.7 \times 10^{5}, 3.4 \times 10^{5}, 2.4 \times 10^{5}$, and $2.4 \times 10^{5}$, respectively, as described in the preceding paper, were fractionated in $0.2 \mathrm{M} \mathrm{NaCl}$ aqueous solutions by the successive precipitation method with acetone as the precipitant. Each sample was separated into four fractions, each of which was dissolved in $1 \mathrm{mM} \mathrm{NaCl}$ and freeze-dried for storage. The molecular weight and molecular weight distribution were determined by means of intrinsic viscosity $\left(25^{\circ} \mathrm{C}\right)$, GPC $\left(20^{\circ} \mathrm{C}\right)$, and gel electrophoresis $\left(0^{\circ} \mathrm{C}\right)$, and compared with those of unfractionated samples. The molecular weight of each fractionated DNA sample was found to be in the range between $0.7 \times 10^{5}$ and $7 \times 10^{5}$, while the degree of polydispersity in terms of $M_{w} / M_{n}$ was found to be between 1.06 and 1.77 , any of which is narrower than the values of the corresponding unfractionated sample. The hyperchromicity of each fractionated sample was estimated from the melting curve. It was always larger than $34 \%$, which indicates that the double-stranded helical structure was maintained in the process of fractionation.
\end{abstract}

KEY WORDS Sonicated DNA / Precipitational Fractionation / Molecular Weight / Molecular Weight Distribution / Intrinsic Viscosity / GPC / Gel Electrophoresis /

The chain length often affects the physicochemical properties of rigid and semiflexible macromolecules. ${ }^{1-10}$ In hydrodynamic studies, for example, the experimentally evaluated rotational relaxation $\operatorname{time}^{1-3}$ and the mean radius of gyration ${ }^{4,5}$ are difficult, or sometimes impossible, to be interpreted in terms of the solution conformation, if there exists a broad distribution of lengths or molecular weights in a given polymer sample. In detailed studies of semiflexible polymers, a large number of samples of various lengths are often needed, and each sample should

\footnotetext{
* To whom correspondence should be addressed.
}

have a narrow length distribution, since the dependence of the above physical quantities on chain length must be investigated.

In the study of the solution conformation of DNA, the above requirement may be fulfilled with nearly monodisperse samples of various lengths, which are prepared by fragmenting some special DNA's with restriction enzymes. This procedure is, however, quite tedious and yields each preparation of minute amount; hence, it is not convenient to study many aspects of a particular sample under the identical conditions. In a previous paper (hereafter designated as I), ${ }^{11}$ it was shown that the ultrasonic scission can produce a large amount 
of DNA fragments by a single-batch method and, in addition, the chain length of sonicated DNA (sDNA) can be adjusted by changing the intensity of ultrasonic irradiation. Since those sonicated DNA's were found to be polydisperse regarding the chain length, ${ }^{5-7,11-13}$ the narrowing of the degree of polydispersity is desirable. Precipitational fractionation is suitable for this purpose, but few reports have appeared as yet. As stated in I of this series, we now report the detailed results of the fractionation of sDNA samples and the molecular weight distribution of fractionated samples in comparison with unfractionated preparations.

\section{EXPERIMENTAL}

\section{Materials and Sonication}

A calf thymus DNA sample (Worthington Biochemical Corp., U.S.A.) was dissolved in $0.2 \mathrm{M} \mathrm{NaCl}$ at a concentration of $2 \mathrm{mg} \mathrm{ml}^{-1}$ with due cautions. ${ }^{8}$ The DNA solutions (60$120 \mathrm{ml}$ ) were sonicated under various conditions of ultrasonic irradiation $(20 \mathrm{kHz})$, as described in detail in I. A $0.1 \mathrm{M}$ ethylenediaminetetraacetate (disodium salt; $\mathrm{Na}_{2}$ EDTA) was added by $5 \mathrm{vol}^{\%}$ to each sonicated DNA solution, which was then dialyzed against $0.2 \mathrm{M} \mathrm{NaCl}$ for $5-7$ days at $4^{\circ} \mathrm{C}$, by changing a total of 14 liters of solvent $(0.2 \mathrm{M} \mathrm{NaCl})$ in seven portions.

\section{Fractionation}

Each dialyzed sDNA solution was placed in a vessel, which was set in a constanttemperature bath at $15^{\circ} \mathrm{C}$. As the precipitant, acetone was gradually added through a burette to the solution, which was being stirred gently with a magnetic bar. After the solution was brought to the clouding point, an appropriate quantity of acetone was further added to the solution to obtain a proper amount of the sDNA precipitate. The vessel containing this turbid solution was set in another bath and warmed to $25-30^{\circ} \mathrm{C}$ to redissolve the pre-
Table I. Fractionation of sonicated DNA and the recovery of fractionated samples

\begin{tabular}{|c|c|c|c|}
\hline \multirow{2}{*}{ Sample } & Mass/Vol ${ }^{\mathrm{b}}$ & C.p..$^{\mathrm{c}}$ & Recovery $^{d}$ \\
\hline & $\mathrm{mg} / \mathrm{ml}$ & $\%$ & $\%$ \\
\hline $\mathrm{V}(25)$ & $273 / 180$ & 62 & 75 \\
\hline $\operatorname{VII}(60)$ & $305 / 201$ & 65 & 85 \\
\hline IX(105) & $361 / 238$ & 61 & 81 \\
\hline $\mathrm{XI}(200)$ & $361 / 238$ & 61 & 85 \\
\hline
\end{tabular}

a These samples are the same as those used in I. Numerals in parentheses indicate the irradiation intensity in watts.

b The mass of sDNA and the volume of solution for fractionation. The mass of one milligram of anhydrous sDNA free from additives corresponds to $3.03 \times 10^{-6}$ mole of phosphorus atoms. ${ }^{11}$

c Clouding point in vol\% caused by acetone which is added to the solution.

d Final mass of DNA recovered relative to the initial mass of sDNA in $w t \%$.

cipitate. The vessel was then stood overnight in the original bath at $15^{\circ} \mathrm{C}$ for reprecipitation. The precipitate was separated by centrifugation, collected, and then dissolved in $0.1 \mathrm{mM} \mathrm{NaCl}$. This solution was freeze-dried for $10-12 \mathrm{~h}$, enough to remove the remaining acetone. The fluffy or powderlike sDNA fraction was obtained; this was denoted as F1. To the remaining clear supernatant solution after centrifugation, an appropriate amount of acetone was further added to obtain the second precipitate. This precipitate was treated in the same manner as F1, and the freeze-dried sample was denoted as F2. Those manipulations were repeated to obtain the third and fourth fractions which were denoted as F3 and F4, respectively. All freeze-dried sDNA fractions were stored at $-15^{\circ} \mathrm{C}$ in a freezer.

Table I shows the conditions for precipitational fractionation. The recovery of sDNA precipitated by the addition of acetone was $85-75 \%$, partly because of the sDNA loss by successive manipulations and partly because of the lower molecular weight DNA remaining unprecipitated in solution even in excess 
of acetone.

\section{Methods and Measurements}

The melting profile, GPC, agarose gel electrophoresis, ${ }^{14}$ and viscosity of fractionated and unfractionated sDNA samples were measured in the same manner as described in detail in $\mathbf{I}^{15}$

\section{RESULTS AND DISCUSSION}

\section{Melting Curves of Fractionated sDNA}

Figure 1 shows melting curves of sDNA samples in $10 \mathrm{mM} \mathrm{NaCl}$ solution, which were fractionated from a sonicated sample IX, together with the curves of this and a high molecular weight DNA (hDNA). The fractional absorbance change at $260 \mathrm{~nm}, f=\left(A-A_{\mathrm{n}}\right) /$ $\left(A_{\mathrm{d}}-A_{\mathrm{n}}\right)$, is plotted against the temperature of solution, where $A_{\mathrm{n}}$ is the absorbance of a DNA sample at $20^{\circ} \mathrm{C}, A_{\mathrm{d}}$ is the absorbance at $95^{\circ} \mathrm{C}$, and $A$ is the absorbance at a given temperature. The hyperchromicity, defined as $H=\left(A_{\mathrm{d}}-A_{\mathrm{n}}\right) / A_{\mathrm{n}}$, of those solutions decreased from 41 to $35 \%$ with a further fractionation. On the other hand, the melting temperature $T_{\mathrm{m}}$ scattered with no systematic tendency. Record et al. also reported that the $H$ values are as low as $30-20 \%$ on the lower molecular weight side of DNA samples (in 2.4 M tetraethylammonium bromide solution), which were fractionated from a sonicated DNA sample by the GPC method. ${ }^{7}$ Four causes are possible: (1) the denaturation upon ultrasonic irradiation, (2) the formation of single-stranded region(s) in a double-stranded DNA helix, (3) the denaturation in the fractionation process, and (4) a feature characteristic of the short but native double-stranded DNA. It was shown in I that the $H$ values of sonicated DNA are nearly the same as those of unirradiated hDNA, which indicates that DNA remains intact by ultrasonic irradiation. ${ }^{11}$ It has been reported that the singlestranded regions in double-stranded DNA helices were scissored off by sonication. ${ }^{13}$ In

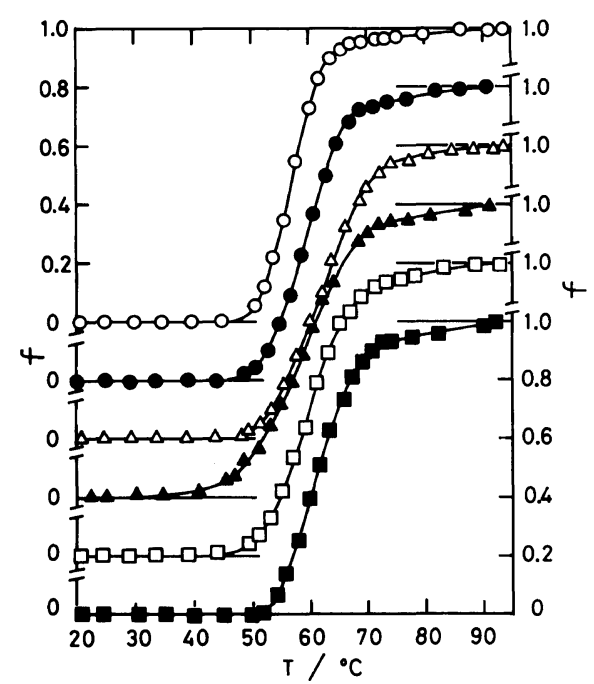

Figure 1. Melting curves of fractionated and unfractionated DNA's (irradiation at $105 \mathrm{~W}$ ) and an unirradiated high molecular weight DNA in $10 \mathrm{mM} \mathrm{NaCl}$. Absorbance was measured at $260 \mathrm{~nm}$ with a $1-\mathrm{cm}$ long absorption cell on a Hitachi Model 139 spectrophotometer. The fractional absorbance change, $f$, was plotted against temperature, $T$. sDNA fractions from sample IX: $\bigcirc,\left(\mathrm{F} 1, H=41 \%, T_{\mathrm{m}}=57^{\circ} \mathrm{C}\right) ;$ $\left.H=40 \%, T_{\mathrm{m}}=60^{\circ} \mathrm{C}\right) ; \triangle,\left(\mathrm{F} 3, H=38 \%, T_{\mathrm{m}}=61^{\circ} \mathrm{C}\right)$; $\Delta,\left(\mathrm{F} 4, H=35 \%, T_{\mathrm{m}}=59^{\circ} \mathrm{C}\right)$. Unfractionated sDNA (sample IX): $\square,\left(H=39 \%, T_{\mathrm{m}}=60^{\circ} \mathrm{C}\right)$. Unirradiated hDNA: $\square,\left(H=40 \%, T_{\mathrm{m}}=61^{\circ} \mathrm{C}\right)$.

Figure 1, both $\mathrm{F} 1$ and $\mathrm{F} 2$ show $H$ values higher than the one observed for the unfractionated mother sample. Those facts sum up to the notion that the lowering of $H$ values with lower molecular weight fractions (F3 and F4) is the property intrinsic to shortchain native DNA's. ${ }^{16}$

\section{Gel Permeation Chromatograph and Gel Electrophoresis of Fractionated and Unfractionated sDNA}

Figure 2 shows chromatograms of unfractionated sample IX (irradiated at $105 \mathrm{~W}$ ) and fractionated samples (F1-F4). The absorbance at $260 \mathrm{~nm}, A_{260}$, of eluent was plotted against the volume of eluent $V$, each chromatogram being so normalized that the area was kept unity for comparison. The half intensity width $V_{w}$ of each fractionated sample is always smaller by $17-40 \%$ than that of unfrac- 


\section{K. FuKudome et al.}

tionated sample IX, indicating that the breadth of molecular weight distribution becomes narrower by fractionation. As fractionation proceeds, the peak elution volumes, $V_{\mathrm{e}}$, of the fractionated samples increase from

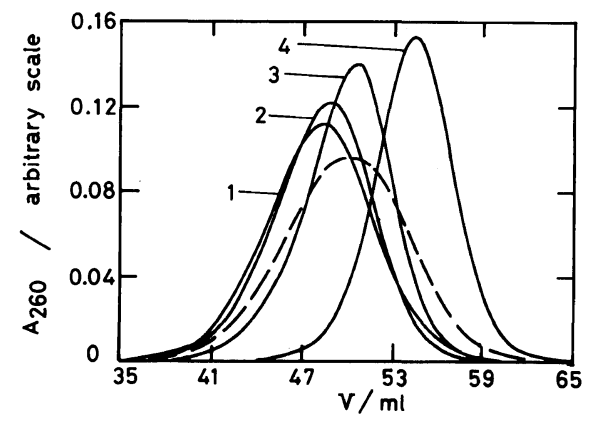

Figure 2. Gel permeation chromatograms of fractionated and unfractionated sDNA's (irradiation at $105 \mathrm{~W})$. (-), the fractionated sample with the fractionation number given by numeral; (-----), unfractionated sample; the loaded volume of each solution, $0.6 \mathrm{ml}$; eluent, $0.2 \mathrm{M} \mathrm{NaCl}$; gel, Sephacryl S-1000 Superfine; flow rate, $8.0-9.6 \mathrm{ml} \mathrm{h}^{-1}$.
48.2 up to $54.4 \mathrm{ml}$; this is a clear indication of the lowering of molecular weight. (Separation of $F 2$ and $F 1$ could have been improved, if the added amount of acetone was adjusted appropriately.) It is now clear from Figure 2 that the molecular weight fractionation was successfully carried out with acetone as the precipitant. Other sonicated samples were fractionated in a similar way with the results given in Table II.

Figure 3 shows the results of gel electrophoresis of the same samples as those in Figure 2. The fluorescence intensity at $590 \mathrm{~nm}$ (excited at $340 \mathrm{~nm}), I_{590}$, of each ethidium-bromidestained gel plate measured at successive points is plotted against the migration distance $x$ from the gel slot to the points (see I for details). As compared with the unfractionated mother sample, each fractionated one yields a smaller half intensity width in electrophoretic pattern, which also reveals a narrower molecular weight distribution. As the fractionation

Table II. Properties of unfractionated and fractionated sDNA samples

\begin{tabular}{|c|c|c|c|c|c|c|c|}
\hline \multirow{2}{*}{ Sample } & \multirow{2}{*}{$\begin{array}{c}\text { Fraction } \\
\text { no. }\end{array}$} & \multirow{2}{*}{$\frac{[\eta]}{10^{2} \mathrm{~cm}^{3} \mathrm{~g}^{-1}}$} & \multirow{2}{*}{$\frac{V_{\mathrm{e}}}{\mathrm{ml}}$} & \multirow{2}{*}{$\frac{V_{\mathrm{w}}}{\mathrm{ml}}$} & \multirow{2}{*}{$M_{w} / M_{n}$} & \multirow{2}{*}{$\frac{M_{w}^{\mathrm{a}}}{10^{4}}$} & \multirow{2}{*}{$\begin{array}{c}H \\
\%\end{array}$} \\
\hline & & & & & & & \\
\hline \multirow[t]{5}{*}{$\mathrm{V}(25)$} & & 4.18 & 44.6 & 14.6 & 1.89 & 57.2 & - \\
\hline & $\mathrm{F} 1$ & 5.73 & 41.5 & 12.5 & 1.57 & 72.7 & - \\
\hline & $\mathrm{F} 2$ & 5.18 & 43.7 & 13.2 & 1.77 & 67.3 & - \\
\hline & F3 & 4.23 & 46.2 & 13.0 & 1.29 & 57.7 & - \\
\hline & $\mathrm{F} 4$ & 1.19 & 52.4 & 7.2 & 1.40 & 22.1 & - \\
\hline \multirow[t]{5}{*}{$\operatorname{VII}(60)$} & & 2.13 & 47.8 & 11.4 & 1.63 & 34.3 & - \\
\hline & $\mathrm{F} 1$ & 3.58 & 46.3 & 9.5 & 1.44 & 50.9 & - \\
\hline & $\mathrm{F} 2$ & 2.86 & 47.3 & 9.3 & 1.44 & 42.9 & - \\
\hline & F3 & 2.38 & 48.8 & 9.2 & 1.60 & 37.4 & - \\
\hline & $\mathrm{F} 4$ & 1.08 & 52.1 & 6.4 & 1.21 & 20.5 & - \\
\hline \multirow[t]{5}{*}{ IX(105) } & & 1.32 & 50.1 & 9.8 & 1.30 & 23.9 & 39.0 \\
\hline & $\mathrm{F} 1$ & 2.41 & 48.2 & 8.1 & 1.29 & 37.7 & 41.3 \\
\hline & $\mathrm{F} 2$ & 2.03 & 48.7 & 7.5 & 1.20 & 33.1 & 40.1 \\
\hline & F3 & 1.15 & 50.5 & 6.5 & 1.18 & 21.5 & 37.9 \\
\hline & $\mathrm{F} 4$ & 0.28 & 54.4 & 5.9 & 1.17 & 7.4 & 35.4 \\
\hline \multirow[t]{5}{*}{ XI(200) } & & 1.32 & 50.7 & 9.6 & 1.59 & 23.9 & 38.5 \\
\hline & $\mathrm{F} 1$ & 2.36 & 48.6 & 8.2 & 1.48 & 37.1 & 41.2 \\
\hline & $\mathrm{F} 2$ & 1.65 & 50.3 & 7.2 & 1.29 & 28.3 & 39.0 \\
\hline & F3 & 0.87 & 52.9 & 5.8 & 1.08 & 17.4 & 39.7 \\
\hline & F4 & 0.29 & 55.3 & 5.5 & 1.06 & 7.6 & 33.7 \\
\hline
\end{tabular}

a These values are calculated from the Eigner and Doty empirical formula. 


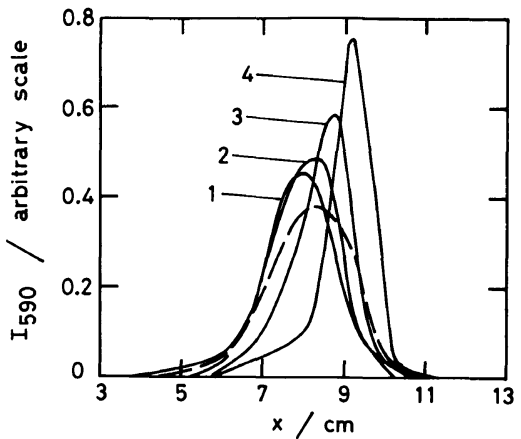

Figure 3. Gel electrophoretic patterns of fractionated and unfractionated sDNA's (irradiation at $105 \mathrm{~W}$ ). Samples and numerals are all the same as those in Figure 2. Each electrophoretic pattern is normalized, so that the area is kept unity.

proceeds, the migration distance increases as in the case of GPC. Similar tendency was observed for other samples sonicated at different levels of ultrasonic irradiation. Since the gel electrophoretic patterns in Figure 3 are very similar to the GPC patterns in Figure 2, the analytical procedure in the following sections may be applied equally well to both GPC and electrophoretic results.

\section{Gel Permeation Chromatography and Mo- lecular Weight Fractionation}

The effectiveness of fractionation with acetone is shown in Figure 4, where the half intensity width $V_{\mathrm{w}}$ is plotted against the peak elution volume $V_{\mathrm{e}}$. In all cases, values of $V_{\mathrm{w}}$ of the unfractionated mother sDNA's are larger than those of the corresponding, fractionated samples. This clearly shows that the molecular weight distribution becomes narrower by fractionation. Values of $V_{\mathrm{e}}$ of fractionated samples are spread widely, while the value for a given unfractionated mother sample is always located in-between, which indicates a successful fractionation. The molecular weights of fractionated samples range between about $7 \times 10^{4}$ and about $70 \times 10^{4}$, as shown in Table II. Hence, it is now possible to prepare an SDNA sample of very low molecular weight with a narrow distribution (e.g., sample IX, F4:

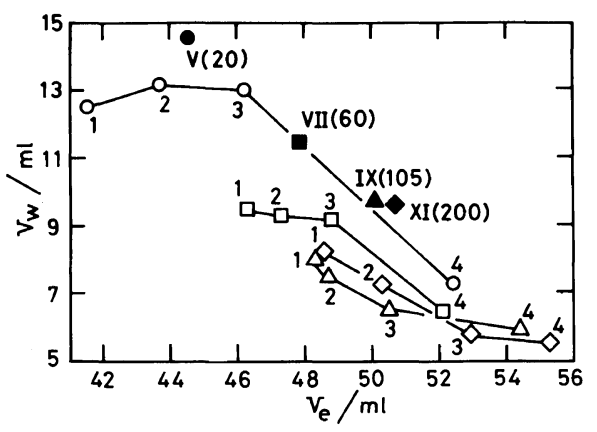

Figure 4. The relationship between the half intensity width $V_{\mathrm{w}}$ and the peak elution volume $V_{\mathrm{e}}$ of fractionated and unfractionated sDNA samples. Filled symbols indicate the unfractionated samples $\mathrm{V}(25)$, VII(60), IX(105), XI(200). The corresponding open symbols indicate the fractionated samples $(1-4)$, which were separated from each unfractionated sample.

$M_{w}=7 \times 10^{4}$, the contour length $\left.=360 \AA\right)$, by irradiating an hDNA at a high irradiation intensity, e.g., $105 \mathrm{~W}$, and by successively fractionating the sonicated DNA sample.

Figure 5a shows the relationship between the intrinsic viscosity $[\eta]$ and the peak elution volume $V_{\mathrm{e}}$ for each fraction in $0.2 \mathrm{M} \mathrm{NaCl}$. In order to make the elution volume $V_{\mathrm{e}}$ independent of a particular gel-filled column, a quantity $K_{\mathrm{av}}$ usable to any column lengths, is defined as $K_{\mathrm{av}}=\left(V-V_{0}\right) /\left(V_{\mathrm{p}}-V_{0}\right)$, where $V_{0}$ is the void volume and $V_{\mathrm{p}}$ is the elution volume of a low molecular weight compound which behaves in the same way as a solvent for the gel material inside a given column. As shown in Figure 5, values of $K_{\mathrm{av}}$ range between 0.4 and 0.8 for all fractionated and unfractionated samples examined in this work. It may be concluded, therefore, that the Sephacryl S-1000 Superfine gel is quite effective in fractionating sonicated DNA samples. Figure $5 \mathrm{~b}$ shows the relationship between the molecular weight $M_{w}$ and the peak elution volume $V_{\mathrm{e}}$ of all sDNA examined. Values of $M_{w}$ of these samples were estimated from the intrinsic viscosity with the empirical formula obtained by Eigner and Doty $([\eta]=1.05 \times$ $10^{-7} M_{w}^{1.32}, M_{w}<2 \times 10^{6} ; c f$. Table II). ${ }^{17}$ 


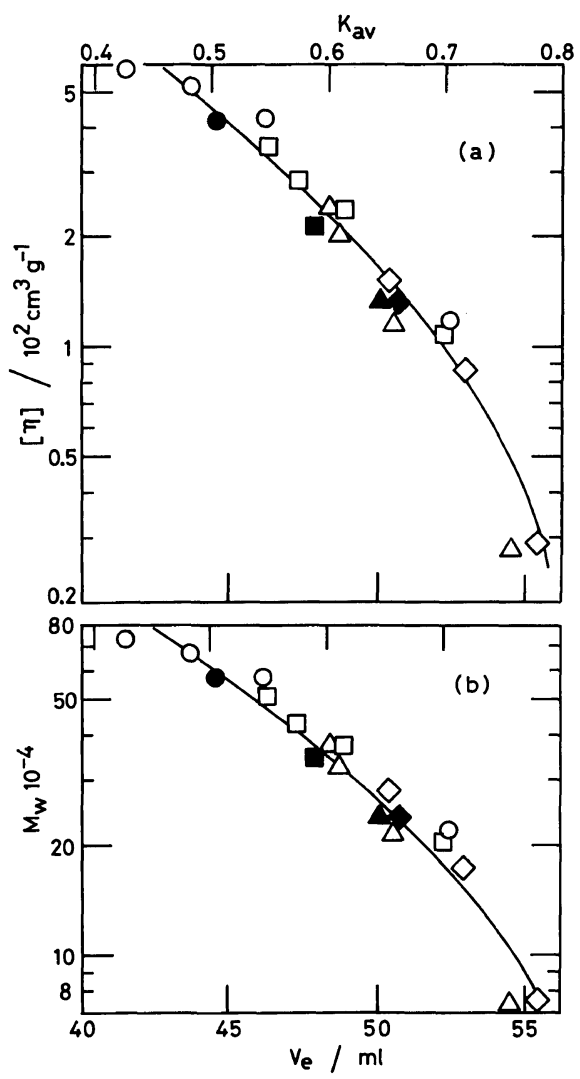

Figure 5. The relationship between the peak elution volume $V_{\mathrm{e}}$ and (a) the intrinsic viscosity [ $\left.\eta\right]$ and (b) the molecular weight $M_{w}$ of fractionated and unfractionated sDNA. $K_{\mathrm{av}}$ is defined in the text. Symbols are the same as those in Figure 4.

In spite of the fact that the GPC method is an easily operative means of separation,,$^{7,18-21}$ it has been applied to the molecular weight fractionation of DNA only ocassionally. Hirose et al. showed that single-stranded DNA's can be fractionated over a molecular weight range of $(3-130) \times 10^{4}$ by using the Sepharose 2B gel. ${ }^{21}$ In the case of doublestranded DNA whose chain is stiff, the Stokes radius is larger than that of the corresponding size random-coiled polymers; hence, the upper limit of molecular weights for fractionation inevitably becomes lower. Because of this, the fractionation of double-stranded DNA has been limited to relatively low molecular weight components. Record et al. could fractionate double-stranded DNA in the molecular weight range between $5 \times 10^{4}$ and $24 \times 10^{4}$ by using the Agarose A-15m gel (Bio-Rad Laboratories). ${ }^{7}$ Prunell and Bernaldi showed that DNA's depolymerized by deoxyribonuclease could be fractionated into double-stranded components whose molecular weights are $(3-30) \times 10^{4}$ by using a Sepharose $6 \mathrm{~B}$ gel. $^{20}$

\section{Gel Electrophoretic Determination of Mo- lecular Weight Distribution}

Because of a high separability and a wide range of fractionation, gel electrophoresis has been used to accurately estimate the chain length (the number of base pairs) of digested DNA fragments. ${ }^{22-24}$ Chiu and Oleinick showed that this method can be utilized not only for the determination of chain length but also for the estimation of molecular weight distribution. ${ }^{25}$ Figure 6 shows the molecular weight distribution curves of sDNA fractionated from two irradiated DNA samples $(\mathrm{a} ; 105 \mathrm{~W}, \mathrm{~b} ; 200 \mathrm{~W})$. The curves, based on the weight of molecule, were estimated from electrophoretic patterns (Figure 3) according to the Chiu and Oleinick method, and are plotted against the number of base pairs, $n$, and the molecular weight, $M$. In each Figure, the peak position shifts toward the smaller molecular weight side as the fractionation proceeds, and the distribution curve shows the skewness toward the higher molecular weight side, which is characteristic of the precipitational fractionation method. The breadth of molecular weight distribution is defined by the ratio of weight- to number-average molecular weights, $M_{w} / M_{n}$, for each sDNA fraction. Values of $M_{w} / M_{n}$ were estimated with the aid of eq 3 and 4 given in $I$ to be in the range of $1.06-1.77$, and are given in Table II. These estimated values are slightly larger than those obtained with the electron-microscopic determination for dried sample by Record et al. ${ }^{7}$ The important difference is in that we used fractional precipitation 


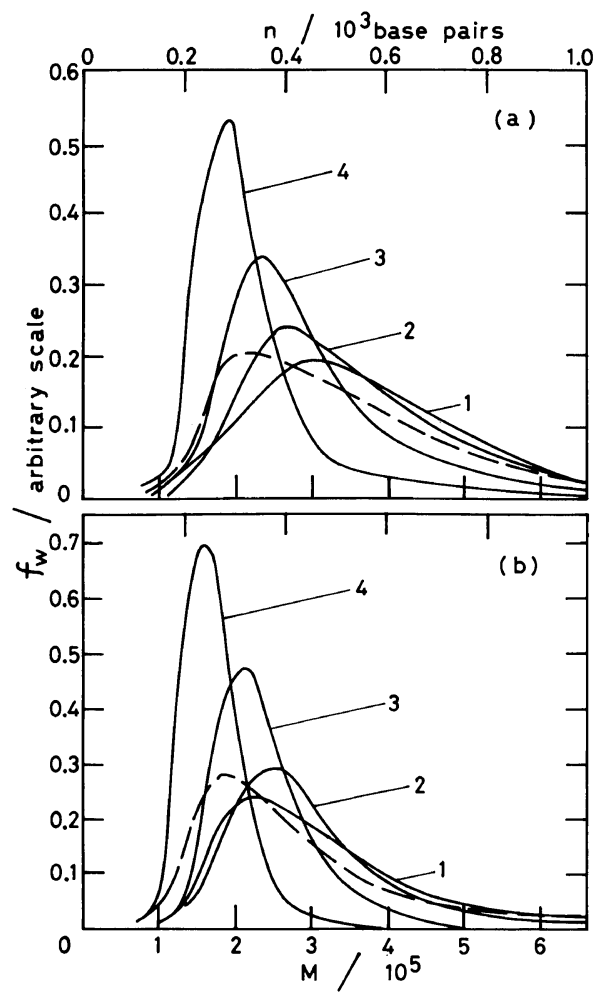

Figure 6. Electrophoretically determined molecular weight distributions of fractionated and unfractionated sDNA. (a): sample IX irradiated at $105 \mathrm{~W}$. (b): sample XI irradiated at $200 \mathrm{~W} . f_{\mathrm{w}}$ is the molecular weight distribution based on the weight of molecule, while $M$ and $n$ are the molecular weight and the number of base pairs in each molecule, respectively. Numerals correspond to those of Figure 2. Solid curves are the fractionated samples with fraction numbers as indicated, while dashed curves are unfractionated samples.

to obtain a few fractionated preparations in large quantities, while Record et al. used a GPC column to successively prepare fractions with narrow distributions in small quantities.

Now we estimate the effect of the diffusion of sDNA on the broadening of an electrophoretic pattern, i.e., the breadth of molecular weight distribution, $M_{w} / M_{n}$. The relationship between the molecular weight and the migration distance $x$ can be approximated with an empirical formula: $M(x)=\exp (-a x+b)$, where $a$ and $b$ are experimentally determined constants. ${ }^{14}$ With the Wesslau distribution, ${ }^{26}$ the breadth of a molecular weight distribution is given as $M_{w} / M_{n}=\exp \left[(a \Delta x)^{2} / 4 \ln 2\right]$, where $\Delta x$ is the half intensity width of an electrophoretic pattern. The $M_{w} / M_{n}$ value obtained from the electrophoretic pattern of a monodisperse DNA should be an apparent one because of the involvement of molecular diffusion. From a multi-peaked electrophoretic pattern of the. HindIII digest of $\lambda$ phage DNA, it was estimated that $a=0.542 \mathrm{~cm}^{-1}$ and $\Delta x=0.3 \mathrm{~cm}$; hence, $M_{w} / M_{n}=1.01$. This indicates that the broadening of electrophoretic pattern by molecular diffusion is negligibly small. Smith et al. reported that the trailing of an electrophoretic pattern depends on the nature of the buffer system to be used and the DNA concentration to be loaded. They recommend a buffer system $(50 \mathrm{mM}$ Tris, $10 \mathrm{mM}$ EDTA, and $30 \mathrm{mM}$ sodium acetate at $\mathrm{pH}$ 8.3) for electrophoresis with a high resolution and without trailing. ${ }^{27}$ In the present work, a closely related buffer system ( $40 \mathrm{mM}$ Tris, $20 \mathrm{mM}$ sodium accetate, and $2 \mathrm{mM} \mathrm{Na}{ }_{2}$ EDTA at $\mathrm{pH} 7.8$ ) was used; hence, the effect of trailing would probably be small, if any. In this work, four sDNA fractions were separated from each sonicated mother sample for the preparative purpose. Samples with narrower molecular weight distribution would, of course, be obtained, if the number of fractionation is increased with a lesser yield.

\section{CONCLUSION}

By the precipitational fractionation method, the molecular weights of DNA samples sonicated on various irradiation conditions were separated successively with acetone as the precipitant. With this method, it is now possible to prepare, routinely and in large amounts, low molecular weight DNA samples with relatively small breadth of molecular weight distribution from high molecular weight calf thymus DNA which was subjected to ultra- 
sonic scission. From GPC and gel electrophoresis, the molecular weights were found to be in the range of $(7-70) \times 10^{4}$, while the breadths of molecular weight distribution were in the range of $1.06-1.77$ in terms of $M_{w} / M_{n}$. The hyperchromicity of samples, which is in the range of $40-35 \%$, led to the conclusion that the fractionated low molecular weight samples maintain the double-helical structure without denaturation. Thus, those sonicated DNA preparations of widely different molecular weights will be very useful for many systematic studies of the solution conformation and other physicochemical properties.

\section{REFERENCES}

1. K. Yamaoka and K. Ueda, Bull. Chem. Soc. Jpn., 56, 2390 (1983).

2. K. Matsuda and K. Yamaoka, Bull. Chem. Soc. Jpn., 55, 1727 (1982).

3. N. C. Stellwagen, Biopolymers, 20, 399 (1981).

4. K. Yamaoka, Bull. Chem. Soc. Jpn., 56, 3499 (1983).

5. J. E. Godfrey, Biophys. Chem., 5, 285 (1976).

6. J. E. Godfrey and H. Eisenberg, Biophys. Chem., 5, 301 (1976).

7. M. T. Record, Jr., C. P. Woodbury, and R. B. Inman, Biopolymers, 14, 393 (1975).

8. E. Charney and K. Yamaoka, Biochemistry, 21, 834 (1982).

9. T. Norisuye, T. Yanaki, and H. Fujita, J. Polym.
Sci., Polym. Phys. Ed., 18, 547 (1980).

10. Y. Kashiwagi, T. Norisuye, and H. Fujita, Macromolecules, 14, 1220 (1981).

11. K. Fukudome, K. Yamaoka, K. Nishikori, T. Takahashi, and O. Yamamoto, Polym.J., 18, 71(1986).

12. A. W. Davis and D. R. Phillips, Biochem. J., 173, 179 (1978).

13. Th. Vreugdenhil, F. van der Touw, and M. Mandel, Biophys. Chem., 10, 67 (1979).

14. O. Yamamoto, M. Ogawa, and M. Hoshi, J. Radiat. Res., 23, 385 (1982).

15. G. Ahnstrom, A. M. George, and W. A. Cramp, Int J. Radiat. Biol., 34, 317 (1978).

16. J. Applequist and V. Damle, J. Am. Chem. Soc., 87, 1450 (1965).

17. J. Eigner and P. Doty, J. Mol. Biol., 12, 549 (1965).

18. W. Muller, H. Schuetz, C. Guerrier-Takada, P. E. Cole, and R. Potts, Nucl. Acids Res., 7, 2483 (1979).

19. Th. Hohn and H. Schaller, Biophys. Biochim. Acta, 138, 446 (1967).

20. A. Prunell and G. Bernardi, J. Biol. Chem., 248, 3433 (1973).

21. S. Hirose, R. Okazaki, and F. Tamanoi, J. Mol. Biol., 77, 501 (1973).

22. N. C. Stellwagen, Biochemistry, 22, 6180 (1983).

23. J. K. Elder, A. Amos, E. M. Southern, and G. A. Shippy, Anal. Biochem., 128, 223 (1983).

24. J. K. Elder and E. M. Southern, Anal. Biochem., 128, 227 (1983).

25. S. Chiu and N. L. Oleinick, Radiat. Res., 82, 146 (1980).

26. H. Wesslau, Makromol. Chem., 20, 111 (1956).

27. S. S. Smith, T. E. Gilroy, and F. A. Ferrari, Anal. Biochem., 128, 138 (1983). 